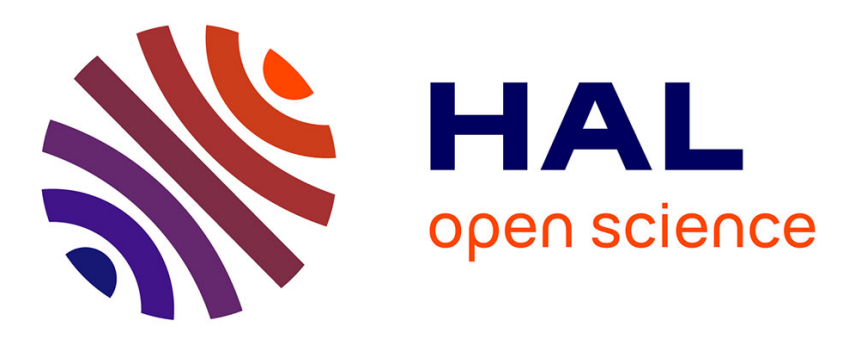

\title{
Multiphysic model for predicting the sound radiation of a single-layer air-core coil
}

Paul Gning, Vincent Lanfranchi, Nicolas Dauchez, Kaiss Bouayed

\section{To cite this version:}

Paul Gning, Vincent Lanfranchi, Nicolas Dauchez, Kaiss Bouayed. Multiphysic model for predicting the sound radiation of a single-layer air-core coil. Applied Acoustics, 2019, 146, pp.327-333. 10.1016/j.apacoust.2018.11.021 . hal-03411618

\section{HAL Id: hal-03411618 https://hal.science/hal-03411618}

Submitted on 2 Nov 2021

HAL is a multi-disciplinary open access archive for the deposit and dissemination of scientific research documents, whether they are published or not. The documents may come from teaching and research institutions in France or abroad, or from public or private research centers.
L'archive ouverte pluridisciplinaire HAL, est destinée au dépôt et à la diffusion de documents scientifiques de niveau recherche, publiés ou non, émanant des établissements d'enseignement et de recherche français ou étrangers, des laboratoires publics ou privés. 


\title{
Multiphysic model for predicting the sound radiation of a single-layer air-core coil
}

\author{
Paul GNING ${ }^{1}$, Vincent LANFRANCHI ${ }^{1}$, Nicolas DAUCHEZ ${ }^{1}$, Kaiss BOUAYED ${ }^{2}$ \\ ${ }^{1}$ Sorbonne Universités, Université de Technologie de Compiègne, CNRS, FRE 2012 Roberval, Centre de recherche Royallieu, CS 60319 , \\ 60203 Compiègne cedex. \\ ${ }^{2}$ ESI Group, Compiègne, France
}

\begin{abstract}
Due to the environmental standards, noise reduction solutions for high voltage devices such as dry-type air-core reactors are needed. The objective this paper is to predict the vibroacoustic response of a single layer air-core reactor from its electrical feed to its acoustical response. Since the coil is a non-ferromagnetic powered conductor placed in a field created by himself, the excitation accounted for is the Lorentz force. The presented multiphysics model couples electromagnetic, mechanical and vibroacoustic numerical softwares. The electromagnetic model gives the distribution and the amplitudes of the Lorentz forces applied on the mechanical structure of the coil. The mechanical model determine the normal modes of the coil of which the Lorentz force are applied. Finally a modal vibroacoustic response is performed. The final and intermediate numerical results are compared to experiments performed on a prototype coil normally intended for the manufacture of loudspeakers, showing a good agreeement.
\end{abstract}

\section{Introduction}

In the face of environmental standards, noise reduction solutions for high-voltage devices like transformers and reactors are needed. These devices generate an electromagnetic field which interaction with the electrical current makes the structure vibrating and emitting noise. In this paper we focus on dry-type air-core reactors used in electric grids. They have several purposes: limiting the fault currents, compensating the loads between two lines in parallel or filtering the current in association with a capacitor. Figure 1 shows an air-core reactor composed of several concentric coils (packages) separated by spacers (sticks) in addition to the non-ferromagnetic structures guaranteeing the mechanical strength.

The state of the art on electromagnetic generated noise has been going on for several decades[1]. Analytical methods and, more recently, numerical methods have been developed depending on the device studied. These devices can be electric machines, transformers or inductors with an iron core 2. Most of the literature focus on devices that include ferromagnetic materials. This type of material induces the presence of forces such as Maxwell's forces but also magnetostriction phenomena.

In the field of rotating machines, Lebesnerais [3] developped an analytical multiphysics model relating maxwell forces to a vibroacoustic model of the machine to perform an optimisation loop. Numerical models [4] allow to get a more detailled information of the noise distribution around the machine. Other studies take into account influential factors such as design [5], temperature [6] or the viscoelastic properties of the resine of the stator[7]. From a vibrational point of view, Baldizzone [8] proposed an experimental procedure to identify critival frequencies to reduce the risk of mechanical damages.

In the field of transformers composed of cores made of ferromagnetic material, recent works present some meth- 


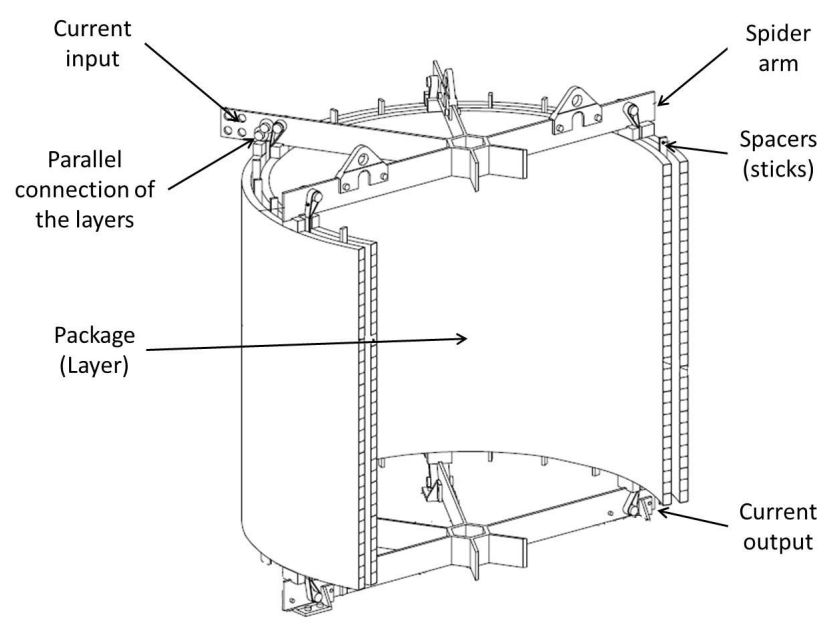

Figure 1: Industrial dry-type air-core reactor.

ods to model the anisotropic behavior for magnetostriction computing to predict the noise generated [9, 10, 11]. An other recent work proposes a multiphysics chaining, taking into account the Maxwell forces in the airgap between the yoke and the column and showing their influence on the noise [12].

Finally, concerning the topic of air-core coils, to the authors's knowledge, no study deals with noise. Extensive work can be found on analytical methods to determine the inductance of solenoid with rectangular cables [13, 14. Some other studies proposed analytical calculations of the magnetic interactions between air-core coils [15, 16, 17].

The objective of this paper is to predict the vibroacoustic behavior of a single layer air-core reactor from its electrical feed to its acoustical response. First the multiphysics model coupling electromagnetic, mechanical and vibroacoustic models is presented. It is then applied to a coil of $0.1 \mathrm{~m}$ diameter and $0.018 \mathrm{~m}$ height (see figure 2), intended for the manufacture of loudspeakers. Experimental results are confronted to predictions at each step of the multiphysics calculation.

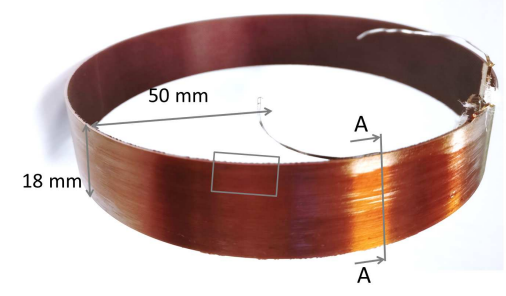

Figure 2: Loudspeaker coil. The grey rectangle is the area where the mesh is zoomed in figure 5

\section{The multiphysics model}

In this section, the multiphysics model associating electromagnetism, structural mechanics and vibroacoustics is described.

\subsection{Therotical background}

When a current density $\vec{J}$ is applied on an air-core reactor, it generates a flux density $\vec{B}$. The current will then interact with the flux density to generate Lorentz forces which density $d \vec{F}_{L}$ is given by:

$$
d \vec{F}_{L}=\vec{J} \times \vec{B}
$$

The Lorentz force is the force exerted on a conductor with a current through it and placed in a magnetic field. In a volume area, the Lorentz force is calcultated by:

$$
\vec{F}_{L}=\int_{V} d \vec{F}_{L} d V
$$

Figure 3 shows the distribution of the Lorentz forces and the flux density on a sectional view of a coil.

Since the finite element model is performed on a cartesian coordinates system $(\vec{x}, \vec{y}, \vec{z})$, we express the current density $\vec{J}$ and the flux density $\vec{B}$ as:

$$
\begin{gathered}
\vec{J}=\left\{\begin{array}{c}
0 \\
0 \\
J_{z} \cos \left(\omega t+\varphi_{0}\right)
\end{array}\right\}\left\{\begin{array}{l}
\vec{x} \\
\vec{y} \\
\vec{z}
\end{array}\right\}, \\
\vec{B}=\left\{\begin{array}{c}
B_{x} \cos \left(\omega t+\varphi_{x}\right) \\
B_{y} \cos \left(\omega t+\varphi_{y}\right) \\
0
\end{array}\right\}\left\{\begin{array}{l}
\vec{x} \\
\vec{y} \\
\vec{z}
\end{array}\right\},
\end{gathered}
$$




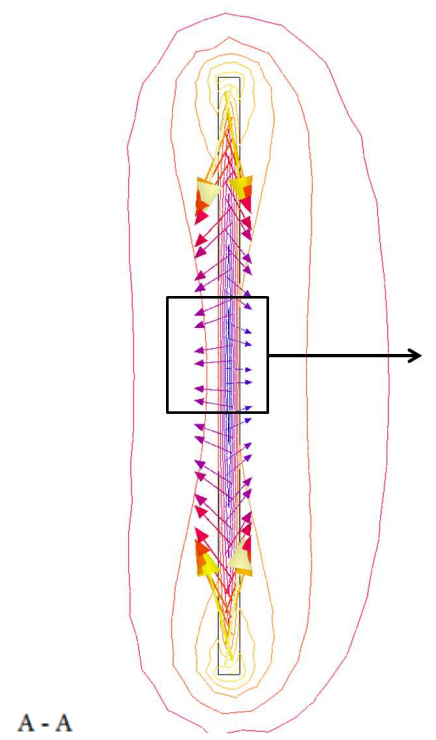

(a)

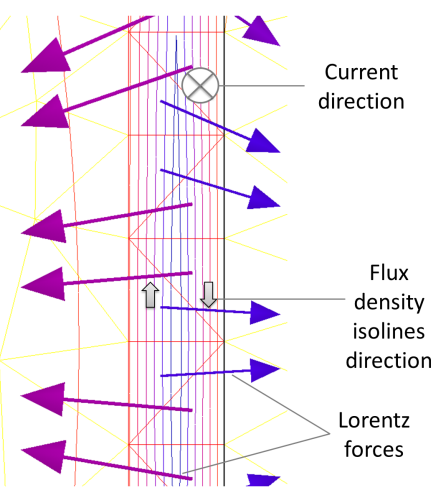

(b)

Figure 3: (a) Sectional view of a coil. (b) Zoom inside the section of the coil with Lorentz forces $F_{L}$ and flux density $B$ isolines and direction. where $\varphi_{x}$ and $\varphi_{y}$ are the phases of the flux density $B$ in $\vec{x}$ and $\vec{y}$ directions, $\varphi_{0}$ is the phase of the current density and $\omega$ is the current pulsation. At a given point, the Lorentz force density is given by:

$$
d \vec{F}_{L}=\left\{\begin{array}{c}
\frac{J_{z} B_{y}}{2} \cos \left(\varphi_{y}-\varphi_{0}\right)+\frac{J_{z} B_{y}}{2} \cos \left(2 \omega t+\varphi_{y}+\varphi_{0}\right) \\
\frac{J_{z} B_{x}}{2} \cos \left(\varphi_{x}-\varphi_{0}\right)+\frac{J_{z} B_{x}}{2} \cos \left(2 \omega t+\varphi_{x}+\varphi_{0}\right) \\
0
\end{array}\right\}\left\{\begin{array}{c}
\vec{x} \\
\vec{y} \\
\vec{z}
\end{array}\right\}
$$

Equation (5) shows that the Lorentz forces have a continuous and a component pulsating at twice the frequency of the current.

After calculating the Lorentz force, a mechnical calculation is performed and the modal basis is determined by:

$$
\left[\mathbf{K}-\omega^{2} \mathbf{M}\right] \Theta_{m}=0
$$

where $\mathbf{K}$ is the stiffness matrix, $\mathbf{M}$ is the mass matrix, $m$ is the rank of the mode and $\Theta_{m}$ is the modal basis. Since we perform a modal computation, the forces $F_{L}$ are obtained as modal forces $F_{L m}$ by the projection of the forces on the modal basis:

$$
F_{L m}=\int_{V} \Theta_{m}(x, y, z) \cdot d F_{L}(x, y, z) d V .
$$

These Lorentz forces are then used to calculate the accelerations and the sound pressure level on the structure in a coupled vibroacoustics calculation written by:

$$
\left[\mathbf{K}(1+j \eta)-\omega^{2} \mathbf{M}\right] W=F_{L m}+P
$$

where $\eta$ is the structural damping coefficient, $W$ is the displacement field and $P$ is the acoustic pressure at the surface of the coil.

Finally the acoustic pressure is calculated by using the integral equation

$$
P(M)=\int_{S}\left(-\rho \bar{\gamma} G(M, N)-P(N) \frac{\partial G(M, N)}{\partial n_{N}}\right) d S_{N},
$$

where $M$ is an outside point of the coil, $N$ is a point on the surface of the coil, $S$ is the surface, $\rho$ is the mass density of the external acoustic media, $\bar{\gamma}=-\omega^{2} W$ is the acceleration field calculated on the surface. $G(M, P)$ is the free field 


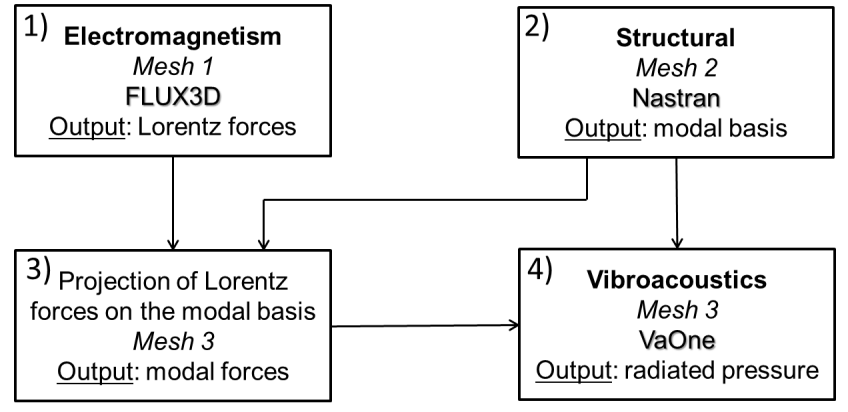

Figure 4: The 4 steps of the multiphysics computation process.

Green's function defined by $G=-e^{i k R} / 4 \pi R$ where $R$ is the distance between two points located in the external acoustic domain in $\mathrm{R}^{3}$ space, $k=\omega / c$ is the acoustic wave number and $c$ is the speed of sound.

\subsection{Computational process}

The multiphysics computational process is composed of 4 steps as shown in figure 4

- The step 1 is an electromagnetic calculation using Altair Flux3D software, a software that solves the Maxwell equations. The input is the electric current density $\vec{J}$ and the output is Lorentz forces $\vec{F}_{L}$ in the volume of the coil's conductor. The results are computed in harmonic regime which means at a single frequency component.

- The step 2 is the calculation of the vibration modal basis with MSC Nastran software.

- The step 3 is the projection of the Lorentz forces on the modal basis.

- The step 4 includes the use of the modal basis and the modal forces in ESI VAOne to perform a coupled mechanical and acoustic calculation.

The interfaces between the electromagnetic and mechanical models are tools specifically developed to ensure the transfer and projection of Lorentz forces field from electromagnetic mesh to the mechanical mesh and guarantee that volume forces are properly taken into account. In addition,

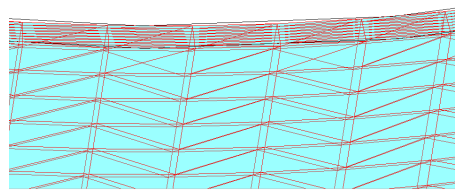

(a)

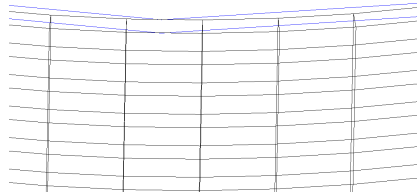

(b) (c)

Figure 5: Zoom on the meshes (see location in figure 22: (a) 3D thetrahedron mesh for electromagnetic computation, (b) 3D hexahedron mesh for mechanical computation and (c) 2D triangle mesh for acoustical computation.

the meshes associated to perform this multiphysics computation are different and depends on the physics accounted for (figure 5). Firstly, for the electromagnetic computation, it is necessary to mesh either the coil and an the surrounding air volume. Moreover, we finely discretize the interior volume of the coil's conductor to be able to see the variations of the flux density $\vec{B}$. So, a tetrahedron mesh is used to generate a mesh with small elements inside the conductor ( 8 nodes in the radial width and 12 nodes in the axial direction) and larger elements in air area. The number of elements is 240179,12811 being in the volume of the conductor. Secondly, the mechanical mesh is composed of 1440 hexahedron elements. In the axial direction, the number of nodes is also 12. However a single element in the radial width is sufficient. Finally, the acoustic modeling is conducted using the boundary element method (BEM) which only require a surface mesh of the outer coil's skin (6240 triangle elements and 12 nodes in the axial direction) and the acoustic problem is solved by calculating the jump pressure. 


\begin{tabular}{c|ccc} 
& Value & Unit & Symbol \\
\hline External radius & $5 \mathrm{E}-2$ & $\mathrm{~m}$ & $R$ \\
Height & $1.8 \mathrm{E}-2$ & $\mathrm{~m}$ & $H$ \\
Number of turns & 106 & & $N$ \\
wire length & 33.3 & $\mathrm{~m}$ & $L$ \\
wire width & $6.5 \mathrm{E}-4$ & $\mathrm{~m}$ & $h$ \\
wire thickness & $1.7 \mathrm{E}-4$ & $\mathrm{~m}$ & $e$
\end{tabular}

Table 1: Dimensions of the tested coil.

\begin{tabular}{c|ccc} 
& Value & Unit & Symbol \\
\hline Density & 8920 & $\mathrm{~kg} / \mathrm{m}^{3}$ & $\mu$ \\
Young modulus & 124 & $\mathrm{GPa}$ & $E$ \\
Poisson ratio & 0.33 & & $\nu$
\end{tabular}

Table 2: Properties of copper.

\section{Application to a single layer coil}

\subsection{Description of the coil}

The method described previously is applied on a coil intended for the manufacture of loudspeakers to validate the computationnal process. The coil dimensions are given in table 1. The wire is made of copper which properties are given in table 2 The coil is impregnated with a thin layer of resine and the turns are held together by a kapton former of $0.1 \mathrm{~mm}$ thickness.

\subsection{Electromagnetic results}

The first step of the application is to perform the electromagnetic computation in order to determine the Lorentz forces. The prototype coil is modeled in Altair Flux3D with a sinusoidal current supply of 0.5 A RMS. Figure6a shows the flux density $\vec{B}$ around and inside the conductor. Inside the section of the coil, we can see that the flux density is at highest both ends of the coil section and at lowest at middle of the section. Around the coil, the flux density is higher inside the perimeter of the coil than outside when we consider the same radial distance. Figure $6 \mathrm{~b}$ shows that there are forces on both sides of the conductor. The forces

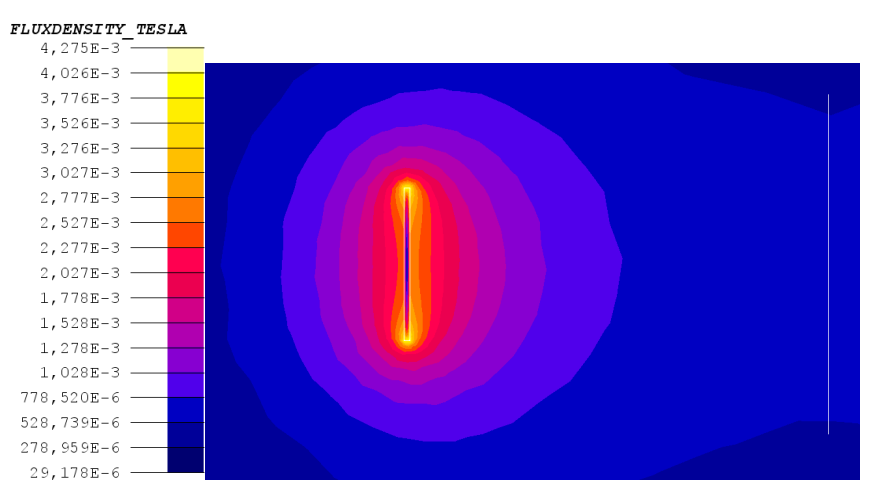

(a)

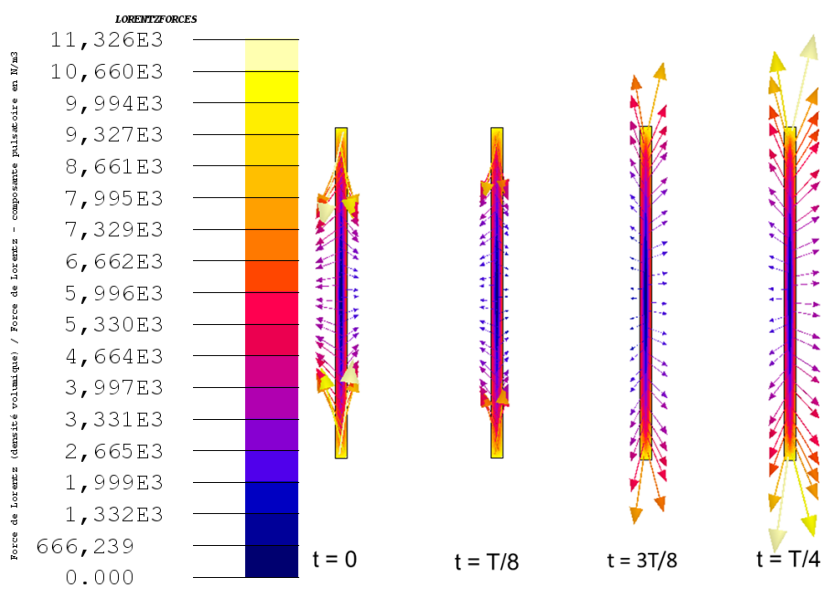

(b)

Figure 6: (a) Flux density distribution. (b) Lorentz forces at 4 different times of the period $T$ of the excitation.

are drawn for several time steps within the period $T$ of the current.

To check the consistency of the electromagnetic model previously presented, tests were carried out. The method consists in measuring, with a teslameter, the flux density generated by the coil. These measurements are compared with the electromagnetic simulations at five points inside the coil. The results are summarized in table 3 . It can be concluded that there is a good agreement between experimental results and the values obtained by finite element simulation: the maximum relative error is less than $5 \%$.

\subsection{Structural results}

Once Lorentz forces are determined, we need the structural modal basis on which these forces will be projected. 


\begin{tabular}{lcccccc}
\hline Position & $\mathrm{r}$ & $-\mathrm{R}$ & $-\mathrm{R} / 2$ & 0 & $\mathrm{R} / 2$ & $\mathrm{R}$ \\
& & \multicolumn{5}{c}{ (center) } \\
\hline \multirow{2}{*}{$\vec{B} \|$} & Tests & 2.34 & 0.89 & 0.75 & 0.87 & 2.31 \\
& Model & 2.3 & 0.84 & 0.72 & 0.84 & 2.3 \\
\hline
\end{tabular}

Table 3: Comparison of measured and simulated flux density values in $\mathrm{mT}$.

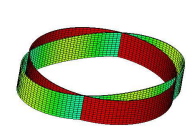

(a) $112 \mathrm{~Hz}$

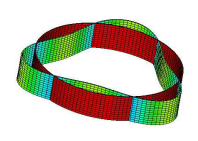

(b) $324 \mathrm{~Hz}$

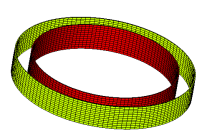

(c) $10909 \mathrm{~Hz}$

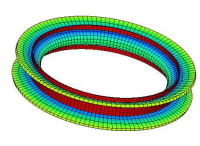

(d) $14021 \mathrm{~Hz}$
Figure 7: Simulated mode shapes and frequencies of 4 modes of the coil: $(2,0)$ mode $(\mathrm{a}),(3,0)$ mode (b), $(0,0)$ mode (c) and $(0,2)$ mode (d).

The coil is modeled in MSC Nastran by an isotropic material with the properties of copper given in table 2. The shape and the frequency of the most contributing modes are given in figure 7. Mode (a) and (b) are non axisymmetrical modes, being at lower frequency in comparison to axisymmetrical modes (c) and (d), the first one being the so-called breathing mode at $10909 \mathrm{~Hz}$.

These results can be compared to an analytical structural model based on the Donnell shell theory for cylindrical shells 18. Here the coil is considered as a ring in free-free boundary conditions. Equations 10 and 11 give respectively the frequency of the breathing mode $(0,0)$ and the frequencies of the radial bending modes $(i, 0)$ :

$$
\begin{aligned}
f_{0} & =\frac{1}{2 \pi R}\left[\frac{E}{\mu\left(1-\nu^{2}\right)}\right]^{\frac{1}{2}}, \\
f_{i} & =f_{0} \frac{h}{2 \sqrt{3} R} \frac{i\left(i^{2}-1\right)}{\sqrt{i^{2}+1}},
\end{aligned}
$$

where $i \geq 2$ is the number of circumferential waves in the mode shape, $E$ is the Young's modulus, $\mu$ is the density, $\nu$ is the Poisson ratio and $R$ is the external radius. Results are given in table 4 .

To verify the validity of the mechanical model, an experimental modal analysis has been performed. A shock hammer and an accelerometer are used. Figure 8 shows the experimental modes shapes of the two first modes. In table 4 the comparison between the frequencies obtained by the finite element computation, the analytical calculation and experiments shows a rather good agreement with a relative error less than $10 \%$, that can be imputed to the resine, the insulation varnish and the kapton former that have not been accounted for. To reduce the relative error, the copper Young's modulus is adjusted to $103 \mathrm{GPa}$. Finally, the modal loss factors are estimated and given in table. These values correspond to a slightly damped structure. They will be used in the vibroacoustic model.

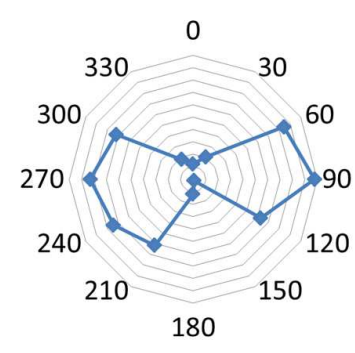

(a)

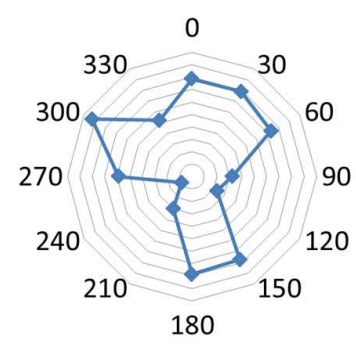

(b)
Figure 8: Experimental mode shapes of $(2,0)$ mode (a) and $(3,0)$ mode (b).

\subsection{Vibroacoustic results}

In the last step, the Lorentz forces are projected on the modal basis in order to perform the coupled vibroacoustics computation.

Figure 9 gives the amplitude of modal forces and the acoustic response at several points around the coil as function of frequency. The response of several structural modes such as the radial bending modes $(2,0)$ and $(3,0)$ can be clearly seen. However mode $(0,0)$ induces the higher pressure. This can be explained by the optimal projection of the Lorentz forces on the breathing mode as shown in figure 9a. The Lorentz forces also project themselves better on the radial-axial mode $(0,2)$ than on the radial bending 


\begin{tabular}{|c|c|c|c|c|c|c|}
\hline & $\begin{array}{c}\text { Ring } \\
\text { mode } \\
(i, j)\end{array}$ & $\begin{array}{c}\text { Rank } \\
m\end{array}$ & $\begin{array}{l}\text { Eq. } 8 \\
\text { and } \\
11\end{array}$ & FEM & Exp. & $\begin{array}{c}\text { Error } \\
\text { FEM- } \\
\text { Exp. }\end{array}$ \\
\hline \multirow{4}{*}{ (a) } & $(2,0)$ & 7 & 136 & 124 & 112 & $10 \%$ \\
\hline & $(3,0)$ & 11 & 386 & 353 & 318 & $10 \%$ \\
\hline & $(0,0)$ & 64 & 12572 & 11939 & 10908 & $9 \%$ \\
\hline & $(0,2)$ & 73 & - & 14021 & - & - \\
\hline \multirow{4}{*}{ (b) } & $(2,0)$ & 7 & 118 & 114 & 112 & $1.8 \%$ \\
\hline & $(3,0)$ & 11 & 334 & 324 & 318 & $1.7 \%$ \\
\hline & $(0,0)$ & 64 & 10917 & 10909 & 10908 & $0 \%$ \\
\hline & $(0,2)$ & 73 & - & 12768 & - & - \\
\hline
\end{tabular}

Table 4: Normal modes frequency in $\mathrm{Hz}$ without fitting (a) and with fitting (b).

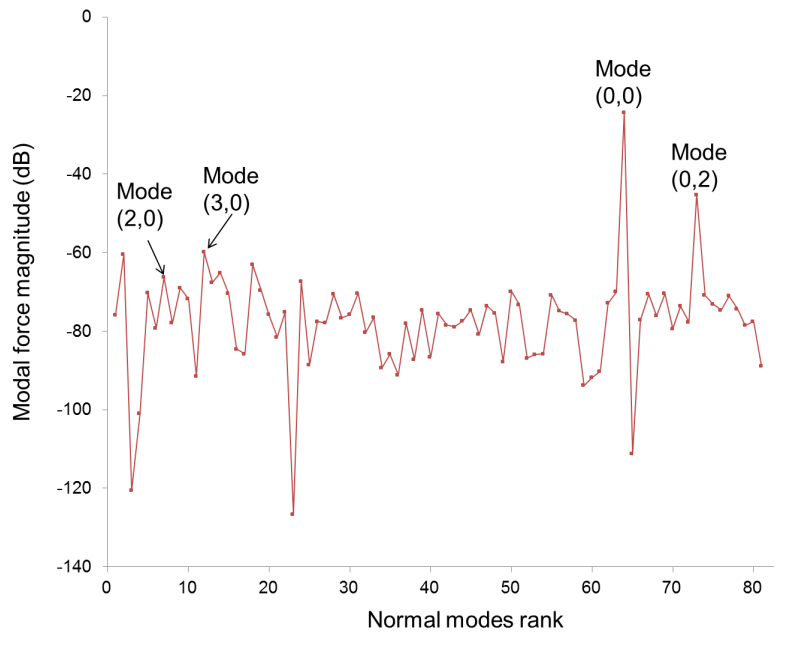

(a)

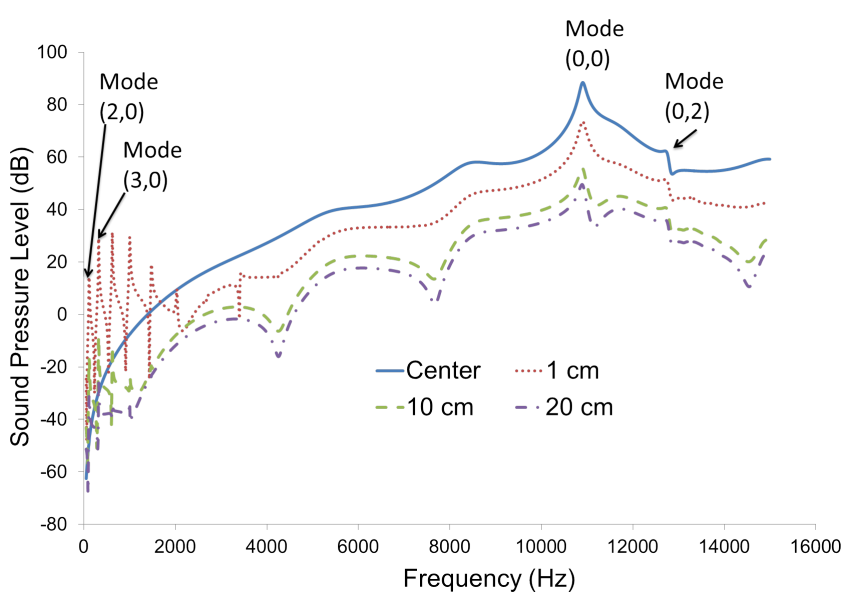

(b)

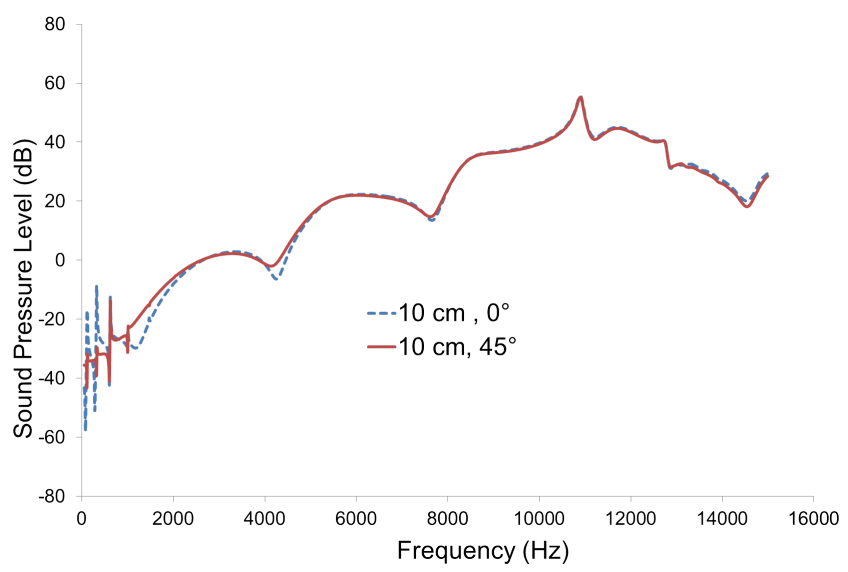

(c)

Figure 9: (a) Amplitude of modal forces. Response of the coil as funcion of frequency at different outside radial distances (b) and angles (c). 


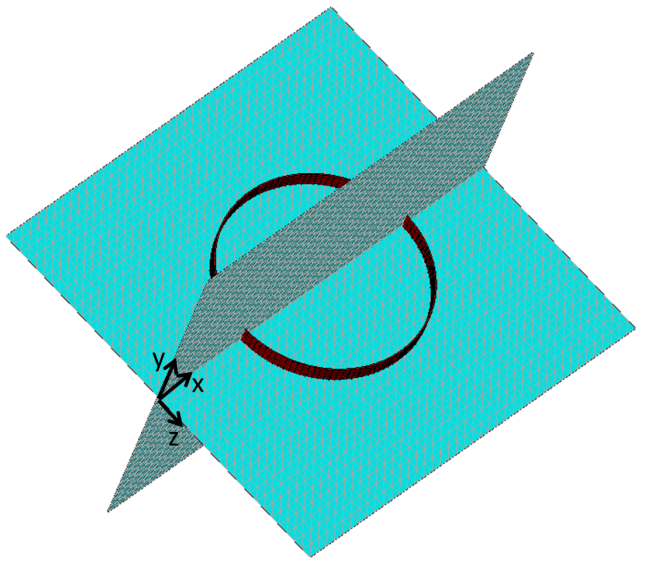

Figure 10: Planes used for results visualization

modes. But its acoustic radiation is much lower than for the mode $(0,0)$.

The magnitude of acoustic field generated at the frequencies of mode $(2,0)$ and $(0,0)$ are plotted in figures $11 \mathrm{a}$ and $11 \mathrm{~b}$ respectively. Figure 10 shows the planes used for results vizualization. Figure 11a shows that the spatial distribution of the pressure magnitude is driven by the mode $(2,0)$ at $114 \mathrm{~Hz}$. There are four maximal pressure areas (maximum at $29 \mathrm{~dB}$ ) separated by lower pressure lines between $-22 \mathrm{~dB}$ and $-30 \mathrm{~dB}$. The minimal pressure magnitude of $-81 \mathrm{~dB}$ is situated on the coil axis. In the same way, figure $11 b$ shows that the spatial distribution of the pressure magnitude is driven by the mode $(0,0)$ at 10909 $\mathrm{Hz}$. The pressure is axisymmetrical with a maximum on the coil axis. Inside the coil, pressure fluctuations between $68 \mathrm{~dB}$ and $92 \mathrm{~dB}$ related to the acoustical wavelength are observed.

Figure $9 \mathrm{~b}$ shows that the radiated pressure decreases quickly with the distance from the coil and that the breathing mode $(0,0)$ still produces the higher acoustical level. Finally figure 9c shows that the near field response is dependent on the angle around the coil only at low frequencies, i.e. below $2000 \mathrm{~Hz}$. The acoustical field is nearly axisymetrical above, which indicates the strong inlfuence of the breathing mode on a large frequency range.
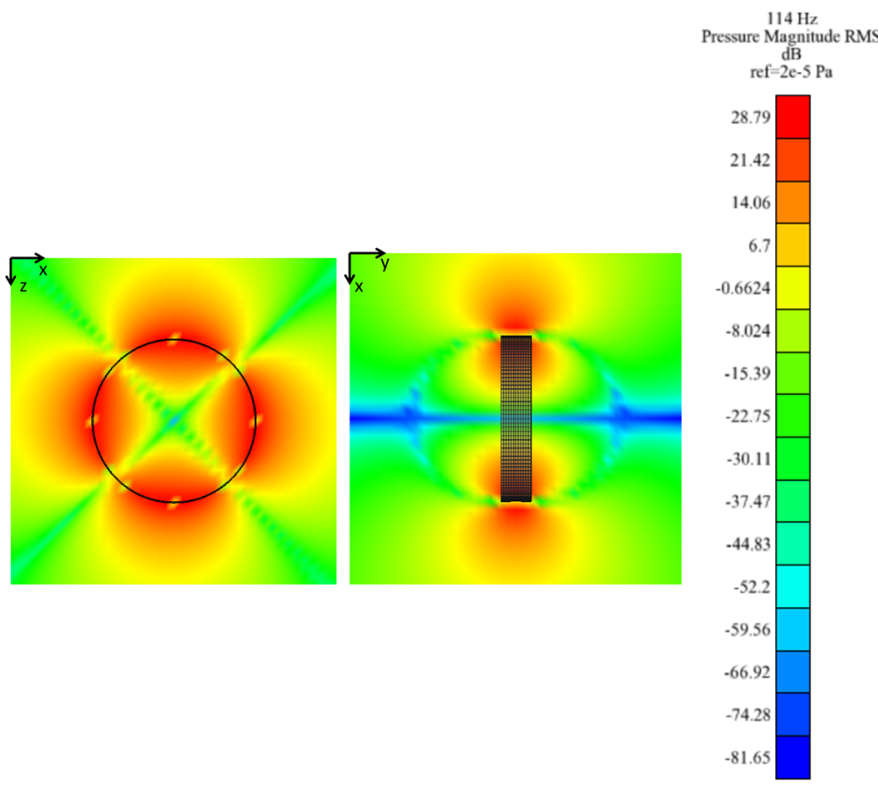

(a)
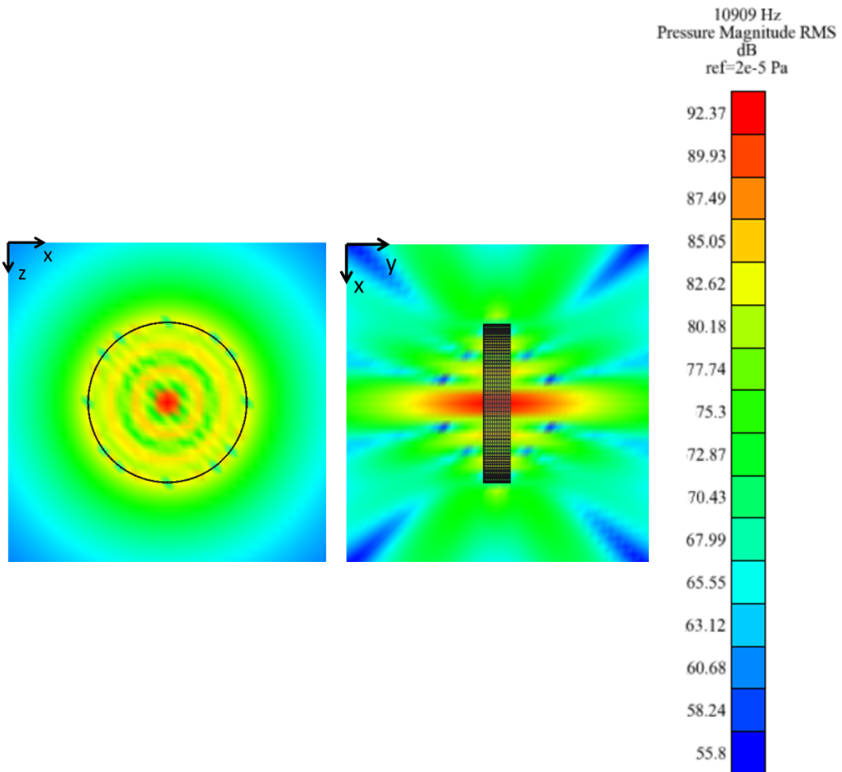

(b)

Figure 11: Map of pressure level for mode $(2,0)$ (a) and for mode $(0,0)$ (b) in dB (reference $2 \cdot 10^{-5}$ ). 


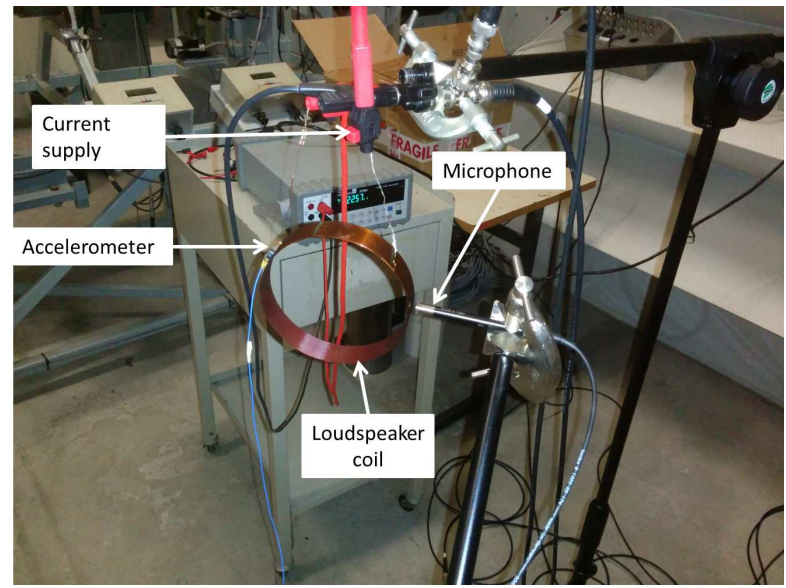

Figure 12: Experimental set-up for sound pressure measurement.

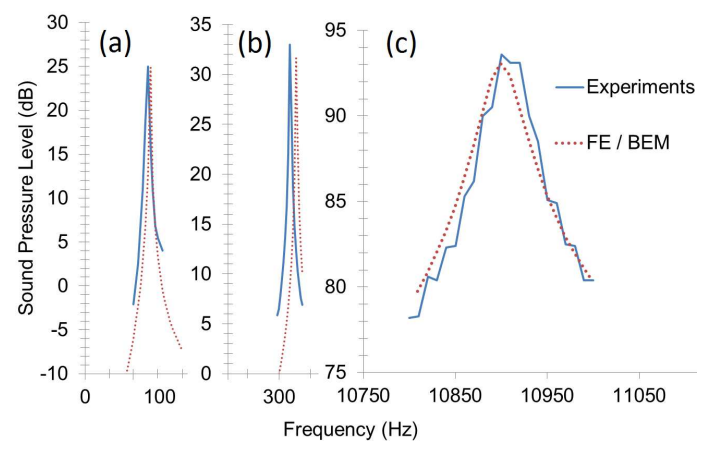

Figure 13: Comparison of the simulated and measured sound pressure levels at frequencies around the structural modes: (a) mode $(2,0)$; (c) mode $(3,0)$; (c) mode $(0,0)$.

\subsection{Comparison with acoustic experimental results}

The final acoustical results are now compared with the experiment. A microphone is positionned at the maximum pressure location inside of the coil around three frequencies where modes $(2,0),(3,0)$ and $(0,0)$ are excited. Free conditions are achieved by suspending the coil (see figure 12. The excitation is a sinusoidal current with a step by step increased frequency.

The comparison of the pressure levels at frequencies around modes $(2,0),(3,0)$ and $(0,0)$, i.e. $112 \mathrm{~Hz}, 320 \mathrm{~Hz}$ and $10900 \mathrm{~Hz}$ respectively, is given in figure 13. A good agreement between the simulation and the experiments is observed.

\section{Conclusion}

A multiphysics method to model an air-core coil from its electric sinusoidal feed to its vibroacoustic response was proposed. It consists in chaining electromagnetic, structural and vibroacoustic models. These models were all succesfully compared to dedicated experiments. The final acoustic results, focused on the first radial bending modes and on the breathing mode, are in good agreement with the experiment. It is shown that the breathing mode is the one producing the highest sound pressure level, and is dominating a large frequency range.

The next step of this work will be dedicated to a parametric study on industrial dry-type air-core reactors.

\section{Aknowledgements}

The authors wish to thans RTE for their financial support.

\section{References}

[1] J. F. Gieras, Z. J. Wang, and J. C. Lai, Noise of Polyphase Electric Motors. CRC Press, 2005.

[2] F. Devaux, S. Ryder, and M. Rosner, "Bruit genere par les transformateurs et bobines d inductances : differents types et differentes solutions," Alstom T\&SD, 2003.

[3] J. L. Besnerais, A. Fasquelle, M. Hecquet, J. Pelle, V. Lanfranchi, S. Harmand, P. Brochet, and A. Randria, "Multiphysics Modeling: Electro-VibroAcoustics and Heat Transfer of PWM-Fed Induction Machines," IEEE Transactions on Industrial Electronics, Apr. 2010.

[4] C. Lin and B. Fahimi, "Prediction of Acoustic Noise in Switched Reluctance Motor Drives," IEEE Transactions on Energy Conversion, Mar. 2014. 
[5] A. Tan-Kim, V. Lanfranchi, S. Vivier, J. Legranger, and F. Palleschi, "Vibro-acoustic simulation and optimization of a claw-pole alternator," in 2015 IEEE Energy Conversion Congress and Exposition (ECCE), Sep. 2015.

[6] A. Tan-Kim, V. Lanfranchi, J. Legranger, F. Palleschi, and M. Redon, "Influence of temperature on the vibro-acoustic behavior of claw-pole alternators," in 2014 International Conference on Electrical Machines (ICEM), Sep. 2014.

[7] P. Millithaler, J.-B. Dupont, M. Ouisse, m. SadouletReboul, and N. Bouhaddi, "Viscoelastic property tuning for reducing noise radiated by switched-reluctance machines," Journal of Sound and Vibration, pp. 191208, Oct. 2017.

[8] S. Baldizzone, C. J. Novak, and N. C. Kar, "Experimental investigations of noise and vibration in electric machines," in 2012 IEEE Transportation Electrification Conference and Expo (ITEC), Jun. 2012, pp. 1-6.

[9] S. S. Mbengue, N. Buiron, and V. Lanfranchi, "Macroscopic modeling of anisotropic magnetostriction and magnetization in soft ferromagnetic materials," Journal of Magnetism and Magnetic Materials, 2016.

[10] P. Shuai and J. Biela, "Impact of core shape and material on the acoustic noise emission of medium frequency, medium voltage transformers," in 2015 17th European Conference on Power Electronics and Applications (EPE'15 ECCE-Europe), Sep. 2015, pp. 1-11.

[11] S. S. Mbengue, N. Buiron, and V. Lanfranchi, "An Anisotropic Model for Magnetostriction and Magnetization Computing for Noise Generation in Electric Devices," Sensors (Basel, Switzerland), Apr. 2016.

[12] K. Bouayed, L. Mebarek, V. Lanfranchi, J.-D. Chazot, R. Marechal, and M.-A. Hamdi, "Noise and vibration of a power transformer under an electrical excitation," Applied Acoustics, pp. -, 2017.

[13] J. Conway, "Inductance Calculations for Circular Coils of Rectangular Cross Section and Parallel Axes Using Bessel and Struve Functions," IEEE Transactions on Magnetics, Jan. 2010.

[14] Y. Luo and B. Chen, "Improvement of Self-Inductance Calculations for Circular Coils of Rectangular Cross Section," IEEE Transactions on Magnetics, Mar. 2013.

[15] S. Babic, F. Sirois, C. Akyel, G. Lemarquand, V. Lemarquand, and R. Ravaud, "New Formulas for Mutual Inductance and Axial Magnetic Force Between a Thin Wall Solenoid and a Thick Circular Coil of Rectangular Cross-Section," IEEE Transactions on Magnetics, vol. 47, no. 8, pp. 2034-2044, Aug. 2011.

[16] Z. J. Wang and Y. Ren, "Magnetic Force and Torque Calculation Between Circular Coils With Nonparallel Axes," IEEE Transactions on Applied Superconductivity, vol. 24, no. 4, pp. 1-5, Aug. 2014.

[17] R. Ravaud, G. Lemarquand, S. Babic, V. Lemarquand, and C. Akyel, "Cylindrical Magnets and Coils: Fields, Forces, and Inductances," IEEE Transactions on Magnetics, vol. 46, no. 9, pp. 3585-3590, Sep. 2010.

[18] R. D. Blevins, Formulas for Natural Frequency and Mode Shape, 1979. 